\title{
Bioplastics for Food Packaging: A Review
}

\author{
Rukhsana Rahman*, Monika Sood, Neeraj Gupta, Julie D. Bandral, \\ Fozia Hameed and Shafia Ashraf
}

\author{
Division of Food Science and Technology, S. K. University of Agricultural Sciences and \\ Technology of Jammu, Chatha - 180 009, J \& K, India
}

*Corresponding author

\section{Keywords \\ Petrochemical plastics, Bioplastics, Biodegradable packaging, Blend, Recyclable, Renewable resources, Agricultural byproducts, Biopolymers, nanofillers \\ Article Info \\ Accepted: \\ 20 February 2019 \\ Available Online: \\ 10 March 2019}

\section{A B S T R A C T}

In the past years, various studies have been done on biodegradable materials to replace petroleum based plastics for food packaging application. For this purpose, biopolymers are considered the most favorable material because of their biodegradable nature and long shelf life properties like resistance to chemical or enzymatic reactions. Keeping in view the non-renewable nature and waste disposal problem of petroleum based plastics; newer concept of use of bioplastics came into existence. Bioplastics are derived from renewable resources i.e. produced from agro/food sources, materials such as starch, cellulose, protein etc. used for packaging materials and which are considered safe to be used in food applications. Bioplastics made from renewable sources are compostable or degradable by the enzymatic action of micro-organisms and gets hydrolysed into $\mathrm{CO}_{2}, \mathrm{CH}_{4}$, inorganic compounds or biomass. The beneficial uses of bio-origin materials obtained from microbial fermentations, starch and cellulose has led to their immense innovative uses in food packaging in the last few years. The biodegradable packaging materials are highly beneficial in one time use or short-duration packaging requirements. The main function of biodegradables like any other packaging material is to protect the contents from surrounding and maintain its quality throughout the storage life. They are widely used to pack low shelf life products, like fresh fruits and vegetables, and high shelf life products, like pasta and chips, which does not require very high oxygen and/or water barrier properties. To increase the mechanical properties, and water barrier properties, the bioplastics can be blended easily with other biopolymer as well as nanofillers. The dependency on limited petroleum resources has been reduced with the developments in the bio-based packaging. Thus, the bioplastics serve as an eco-friendly substitute for the use of non-renewable and non-biodegradable plastic based packaging materials and the study of recyclable and biodegradable polymers is fascinating and developing area in packaging science.

\section{Introduction}

Food packaging is a prerequisite element in the food industry, concerns with protection and preservation of all types of foods and is prevalent by petroleum-derived plastics. Petrochemical-based plastics such as polyvinylchloride (PVC), polypropylene (PP), 
polyethylene terephthalate (PET), polyethylene (PE), polyamide (PA) and polystyrene (PS) have been progressively used as packaging materials because their good mechanical performance such as tear and tensile strength, good barrier to carbon dioxide, oxygen, anhydride and aroma compound, and heat sealability and because their huge availability at relatively low cost (Siracusa et al., 2008). Increased use of petroleum based plastics has both environmental and health hazards. It also affects the health of workers who are related with cleaning or maintaining the processing equipments which led to serious ecological problems due to their total nonbiodegradability (Jayasekar et al., 2005).

Due to the increasing environmental concerns created by excessive plastic accumulation, interest has shifted towards the development of such packaging materials that not only improve performance but are also easy to recycle and reuse i.e., "bio-plastics". According to the European Bioplastics organization, bioplastics can be defined as plastics based on renewable resources (biobased) or as plastics which are biodegradable and/or compostable polymers. Bioplastics are derived from different renewable sources such as vegetable oil, corn starch, potato starch, fibres obtained from pineapple, jute, hemp, henequen leaves and banana stemsand also from used plastic bottles and other containers using microorganisms (Siracusa et al., 2008; Sudesh and Iwata, 2008).

Biodegradable polymers are polymers that are capable of undergoing decomposition into $\mathrm{CO}_{2}, \mathrm{CH}_{4}, \mathrm{H}_{2} \mathrm{O}$, and inorganic compounds under suitable conditions of temperature, moisture, and oxygen or biomass through predominantly the enzymatic action of microorganisms (Song et al., 2009). Thus the biodegradable packaging materials are those that undergo the process of degradation by naturally occurring organisms, such as bacteria, yeast, or fungi (Sorrentino et al., 2007), and can be used as fertilizer or humus when composted (Siracusa et al., 2008).

Currently, bioplastics represent about one percent of the about 320 million tonnes of plastic produced annually. According to the European Bioplastics in cooperation with the research institute nova-Institute, global bioplastics production capacity is set to increase from around 2.05 million tonnes in 2017 to approximately 2.44 million tonnes in 2022 (European Bioplastic, 2017).

Although bioplastics are considered to develop eco- friendly food packaging materials, they also have some limitations such as poor mechanical and barrier properties and high production cost. But their mechanical and barrier properties can be improved by blending two or more biopolymers and high production cost drawback can be managed by utilizing the low cost of renewable resources such as agricultural wastes (Jain and Tiwari, 2015). Several active components or additives like antimicrobials, color, antioxidants, nutrients, etc. can be incorporated for increasing their performance (Clarinval and Halleux, 2005).

The study of recyclable and biodegradable plastic is an interesting and emerging area in packaging science but massive research is required for improving their performance, mechanical, thermal, and physical characteristics, and commercial use, which might be possible in a few years.

\section{Classification of bioplastics}

Various classification systems based on different criteria's have been proposed to classify these bioplastics, as they can be derived from a large number of renewable sources and it is difficult to restrict them in a 
single class. However, one classification system based on their origin (Fig. 1) divides these bioplastics into three major categories/types.

Natural polymers or polymers derived from biomass.

Synthetic polymers or polymers chemically synthesized from renewable sources.

Microbial polymers or polymers derived from microorganisms.

\section{Natural polymers or polymers derived from biomass}

The natural polymers are derived from animal, marine, and agricultural sources, which include the polysaccharides, such as starch, cellulose, chitosan, gums etc., proteins like plant derived proteins (zein, gluten, soy, etc.) and animal extracted proteins (casein, collagen, gelatin, etc.) and lipids including cross linked triglycerides. By nature most of these polymers are hydrophilic and crystalline in nature, which create several problems while processing in moist food packaging. However they have excellent gas barrier properties which make them acceptable for their utilization in food packaging (Averous and Pollet, 2012).

\section{Starch}

Starch is the most abundant commonly used renewable raw material and easy biodegradable natural resource. It is obtained from seeds, corn, wheat, rice, potato, sweet potato, and cassava (Whistler and BeMiller, 2007). Starch is usually used as a thermoplastic and constitutes a substitute for polystyrene (PS). It is plasticized through destructuration in presence of specific amounts of water or plasticizers (glycerol, sorbitol) and heat and then it is extruded. Starch is an attractive material for packaging applications because of its relatively low cost, availability, and biodegradability. Starch having poor resistance to moisture and their poor mechanical property restricts their use. Therefore to improve these properties starch is blended with various biopolymers and certain additives (Yadav et al., 2018).

\section{Cellulose}

Cellulose is the most abundant natural polymer and is derived by a delignification from wood pulp or cotton linters. Cellulose is very difficult to use in packaging because it is hydrophilic and crystalline in nature possessing poor mechanical properties in its raw form. Therefore, it must be treated with chemicals like $\mathrm{NaOH}, \mathrm{H}_{2} \mathrm{SO}_{4}, \mathrm{CS}_{2}$, etc. to produce cellophane having excellent mechanical characteristics (Majid et al., 2018). Cellulose derivatives can be produced by derivatization of cellulose from the solvated state, via esterification or etherification of hydroxyl group. Cellulose derivative forms are used for films or edible coatings: Hydroxypropyl cellulose, hydroxypropyl methylcellulose, Carboxymethyl cellulose or Methyl cellulose (Majid et al., 2018). Incorporation of hydrophobic compounds is one method for increasing the moisture barrier, such as fatty acids into the cellulose ether matrix to develop a composite film (Morillon et al., 2002).

\section{Chitosan or chitin}

Chitosan or chitin, is the second abundant polysaccharide resource after cellulose found in nature. It naturally appears in the exoskeleton of arthropods and in the cell walls of yeasts and fungi. It is produced commercially by chemical extraction processes from prawns and crabs wastes. Chitosan is obtained from deacetylation of chitin, and different factors (e.g. alkali concentration, incubation time, ratio chitin to 
alkali, temperature and chitin source) can affect its properties (Thakur et al., 2016). Chitosan forms films without the addition of additives, exhibits good carbon dioxide and oxygen permeability, as well as excellent mechanical properties and antimicrobial properties which reduces the oxidation process and is beneficial for increasing the shelf life and quality of food products (Gemili et al., 2009).

\section{Proteins}

Proteins are complex structures made up of amino acids and can be obtained from plant (wheat gluten, corn, zein, soy protein etc.) and animal (casein, whey, keratin, gelatin, etc.) sources. They are highly desirable to modify the required characteristics of packaging materials due to the presence of unique side chain in their structure. Due to the renewable nature, biodegradability and their excellent gas barrier properties proteins and protein based materials find their use in many industrial applications. But they are adversely affected by their hydrophilic nature like starch-based polymers. Therefore, they need to be blended with other polymers or must be chemically or microbiologically modified (Majid et al., 2018).

Casein is a milk-derived protein, when processed with suitable plasticizers at temperature of $80-100{ }^{\circ} \mathrm{C}$, form materials with mechanical performance varying from stiff and brittle to flexible and tough performance. Casein films have an opaque appearance. Irrespective of its relatively high price, it is used today for bottle labeling because of its excellent adhesive properties.

Gluten plastics exhibit high gloss and show good moisture resistance under certain conditions. They do not dissolve in water, but absorb some water on immersion. Research on the use of gluten in edible films, adhesives, or for thermoplastic applications is currently being carried out due to its low cast and abundance (Otles and Otles, 2004).

Soy proteins are commercially available as soy flour, soy concentrate and soy isolate. Soy protein isolate (SPI) may be used to prepare edible and biodegradable packaging films. The films obtained from SPI exhibit excessive friability, so their performance is limited. In order to improve them, they must be modified by the addition of a plasticizer, such as glycerol (Kokoszka et al., 2010).

The cheapest protein, keratin extracted from waste streams such as hair, nails and feathers. Keratin the most difficult protein to process due to its structure and a high content of cysteine groups (Shukla, 1992). On the other hand, whey proteins, byproducts from the cheese industry, are widely employed as edible films and coatings.

Several lipid components like fatty acids, natural waxes, resins, and vegetable oils are generally incorporated in the films to provide hydrophobicity so that moisture barrier properties can be improved.

\section{Synthetic polymers or bioplastics chemically synthesized from renewable sources}

They are produced from classical chemical synthesis from biobased monomers. In this category, polylactic acid (PLA) is one of the most commercially available and exploited bioplastics.

\section{Polylatic acid (PLA)}

PLA one of the most promising and biodegradable polyester made from renewable resources such as corn, sugar beets, and potato starch for commercial use as a substitute for high density polyethylene 
(HDPE) and low density polyethylene (LDPE), polystyrene (PS) and polyethylene terephthalate (PET). It is obtained by conversion of corn, or other carbohydrate sources, into dextrose, followed by fermentation into lactic acid. Through direct polycondensation of lactic acid monomers or through ring-opening polymerization of lactide, PLA pellets are obtained. The processing possibilities of this transparent material are very vast, ranging from injection molding and extrusion over cast film extrusion to blow molding and thermoforming (Rasal et al., 2010)

PLA is becoming an advancing alternative as a green food packaging material because it was found that in many circumstances its performance was better than synthetic plastic materials (Auras, 2005). PLA comes in the form of films, thermo-formed cups and trays, containers and coatings for paper and paper boards etc.

\section{Microbial polymers or polymers derived from microorganisms.}

This class includes the polymers that are synthesized from the microbial fermentation of polysaccharides. It is a quite recent and innovative field that has immense potential in industry. This category includes the polymers, such as polyhydroxyalkanoates (PHA), PHB, etc., and microbial polysaccharides like pullulan, curdlan and xanthan.

\section{Polyhydroxyalkanoates (PHAs)}

The polyhydroxyalkanoates (PHAs) are biodegradable, thermoplastic, biocompatible and thermo stable having melting temperature of about $180{ }^{0} \mathrm{C}$. These polymers are produced in nature via bacterial fermentation of plant-derived feedstocks such as sugars or lipids and then harvested by using solvents such as chloroform, methylene chloride or propylene chloride. These polymers, alone or in combination with starch or synthetic plastic give excellent packaging films (Tharanathan, 2003). Among more than 100 PHAs composites, PHB is the most common type of PHA, coming from the polymerization of 3hydroxybutyrate monomer with properties similar to PP but stiffer and brittle. It degrades under both aerobic and anaerobic conditions forming $\mathrm{CO}_{2}$ and $\mathrm{H}_{2} \mathrm{O}$. Besides being insoluble to water, PHB is optically active and has good barrier properties toward gas (Castilho et al., 2009). The PHAs have potential as an alternative for many conventional polymers, since they possess similar chemical and physical properties. PHAs also exhibit printability, flavor and odor barrier, heat sealability, grease and oil resistance, temperature stability, and are easy to dye which improve its applications in the food industry (Tripathi et al., 2015).

The utilization of several microbial polysaccharides, such as xanthan, pullulan, curdlan, etc., as a packaging film is a novel concept and needs biotechnological techniques.

Pullulan is produced by yeast like fungus Aureobasidium pullulans from substrates containing sugars which are linear, watersoluble and exopolysaccharide (EPS). It is employed for packaging in several industries like food, medicine, and cosmetics. Pullulan based films are edible, homogeneous, transparent, printable, heat sealable, flexible and good barrier to oxygen and are tasteless, odorless, nontoxic, and biodegradable in nature. Pullulan membranes inhibit fungal growth thus making them suitable for food applications particularly (Freitas et al., 2014).

Curdlan, the bacterial polysaccharide, is produced from Agrobacterium biobar and Agrobacterium tumefaciens and is mainly used as a gelling agent in the food industry 
but has enormous potential in the development of packaging films, which is yet to be discovered. On the other hand, Xanthan is produced by the aerobic fermentation of Xanthomonas campestris using sucrose or glucose as its major carbon source and is highly viscous, water soluble and nontoxic in nature. Not much data is available about the potential of xanthan in the packaging sector. This may be due to the high cost of production. However, acerola when wrapped with xanthan coating exhibited reduced weight loss, respiration thus maintaining the color and enhancing the shelf life (Quoc et al., 2015).

\section{Mechanism of biodegradation}

Biodegradation means degradation, disintegration, or loss of mechanical attributes of packaging materials using microorganisms and is preceded by hydrolysis followed by oxidation. The rate of biodegradation depends on temperature (varying from 50 to $70^{\circ} \mathrm{C}$ ), humidity and kind and amount of microorganisms. In industrial composting bioplastics are converted into water, $\mathrm{CO}_{2}$ and biomass, in about 6-12 weeks (Siracusa et al., 2008). The degradation can be aerobic or anaerobic in nature resulting in the formation compost or sludge in the former case and methane and hydrogen (biogas) and in the latter. Natural biopolymers like starch, cellulose, etc. are hydrophilic and swellable in nature in contrast to the polyolefins that are used in central packaging material and are hydrophobic in nature, exhibiting high resistance toward hydrolysis, peroxidation, and biodegradability. Prooxidants must be incorporated in polyolefins to initiate the oxobiodegradation in them. The oxobiodegradation mechanism is followed in the biodegradation of synthetic and natural polymers; however, standard biodegradation require the instant mineralization measure. Further, oxobiodegradation at room temperature is a very slow mechanism as compared to hydrobiodegradation. The oxobiodegradation of carboxylic acid ($\mathrm{COOH}$ ) results in alcohol, aldehyde and ketone molecules, which are degradable using low molar mass generated during the peroxidation that is initiated either by light or heat. This is the main reason the hydrocarbon polymers lose their mechanical properties. After this, bioassimilation starts by the fungal enzymes or bacteria, giving rise to $\mathrm{CO}_{2}$ and biomass that finally produce humus. Generally synthetic polymers contain antioxidants and stabilizers are added to inhibit the oxidation of polymers during biodegradation process and to increase the shelf-life of materials and to improve the performance also (Scott and Wiles, 2001).

\section{Improving the properties of bioplastics}

The bioplastics are associated with several major drawbacks limiting their use in the industry. Thermal instability, brittleness, low melt strength, high water vapor and oxygen permeability, and poor heat sealability etc hinder the commercial use of bioplastics as food packaging (Jamshidian et al., 2010). Therefore, great efforts are being taken to improve the functionality of biopolymers, such as

\section{Coating}

Coating consists of covering of biopolymer using an additional thin film of another material. Several bio-based and non-biobased materials can be used as coating.

For example, PLA can be layered using PCL$\mathrm{Si} / \mathrm{SiOx}, \mathrm{PEO}-\mathrm{Si} / \mathrm{SiOx}$ (polyethylene oxide), or PLA-Si/SiOx, which improves the barrier properties of PLA which makes the PLA films suitable for packaging material (Iotti et al., 2009). 
Chitosan can be employed as a biobased coating for polymers that possess poor gas barrier properties. It can be an efficient and economic technique to improve the performance of polymer. The application of coating improves the barrier properties, such as oxygen permeability and water vapor, grease or oil resistance, and to a little extent, the mechanical properties (elasticity).

\section{Blending}

Blending of two or more biopolymers shows great significance. When we blend materials, compatibility becomes a major challenge. The compatibility for immiscible polymers can be increased by introducing a reactive functional group, chemical modification, or etherification.

Table.1 Applications of bioplastics in food packaging

\begin{tabular}{|c|c|c|c|}
\hline Packaging applications & Biopolymer & Company & References \\
\hline \multicolumn{4}{|l|}{ Starch based } \\
\hline Milk chocolates & Cornstarch trays & $\begin{array}{l}\text { Cadbury Schweppes } \\
\text { food Group, } \\
\text { Marksand Spencer }\end{array}$ & \multirow{2}{*}{$\begin{array}{l}\text { Highlights in Bioplastics, } \\
\text { Website European } \\
\text { bioplastics }\end{array}$} \\
\hline Organic tomatoes & Corn-based packaging & $\begin{array}{l}\text { Iper supermarkets } \\
\text { (Italy), } \\
\text { Coop Italia }\end{array}$ & \\
\hline \multicolumn{4}{|l|}{ Cellulose } \\
\hline Kiwi & $\begin{array}{l}\text { Biobased trays wrapped } \\
\text { with cellulose film }\end{array}$ & Wal-Mart & \multirow[t]{3}{*}{$\begin{array}{l}\text { Blakistone and Sand } \\
(2007)\end{array}$} \\
\hline Potato chips & Metalized cellulose film & Boulder Canyon & \\
\hline Organic pasta & $\begin{array}{l}\text { Cellulose based } \\
\text { packaging }\end{array}$ & Birkel & \\
\hline Sweets & Metalized cellulose film & $\begin{array}{l}\text { Quality street, } \\
\text { Thornton }\end{array}$ & $\begin{array}{l}\text { Highlights in Bioplastics, } \\
\text { Website European } \\
\text { bioplastics }\end{array}$ \\
\hline \multicolumn{4}{|l|}{ Polylactic acid (PLA) } \\
\hline Beverages & PLA Cups & Mosburger (Japan) & Sudesh and Iwata (2008) \\
\hline Fresh salads & PLA Bowls & McDonald's & Haugaard et al., (2003) \\
\hline Coffee and tea & $\begin{array}{l}\text { Cardboard cups coated } \\
\text { with PLA }\end{array}$ & KLM & Jager (2010) \\
\hline $\begin{array}{l}\text { Fresh cut fruits and } \\
\text { vegetables, bakery } \\
\text { goods, salads }\end{array}$ & $\begin{array}{l}\text { Rigid PLA trays and } \\
\text { packs }\end{array}$ & Asda (retailer) & $\begin{array}{l}\text { Koide and Shi (2007) } \\
\text { Jager (2010) }\end{array}$ \\
\hline Yoghurt & PLA jars & Stonyfield (Danone) & $\begin{array}{l}\text { Haugaard et al., (2001), } \\
\text { Jager (2010) }\end{array}$ \\
\hline $\begin{array}{l}\text { Organic fruit and } \\
\text { vegetables }\end{array}$ & PLA packaging & Mont Blanc Primeurs & \\
\hline Pasta & PLA packaging & Biorigin & Highlights in bioplastics \\
\hline Herbs & PLA packaging & Asda (retailer) & \\
\hline
\end{tabular}

Source: Reproduced from Peelman et al., (2013). 
Fig.1 Classification of bioplastic polymers based on origin (Weber et al., 2002)

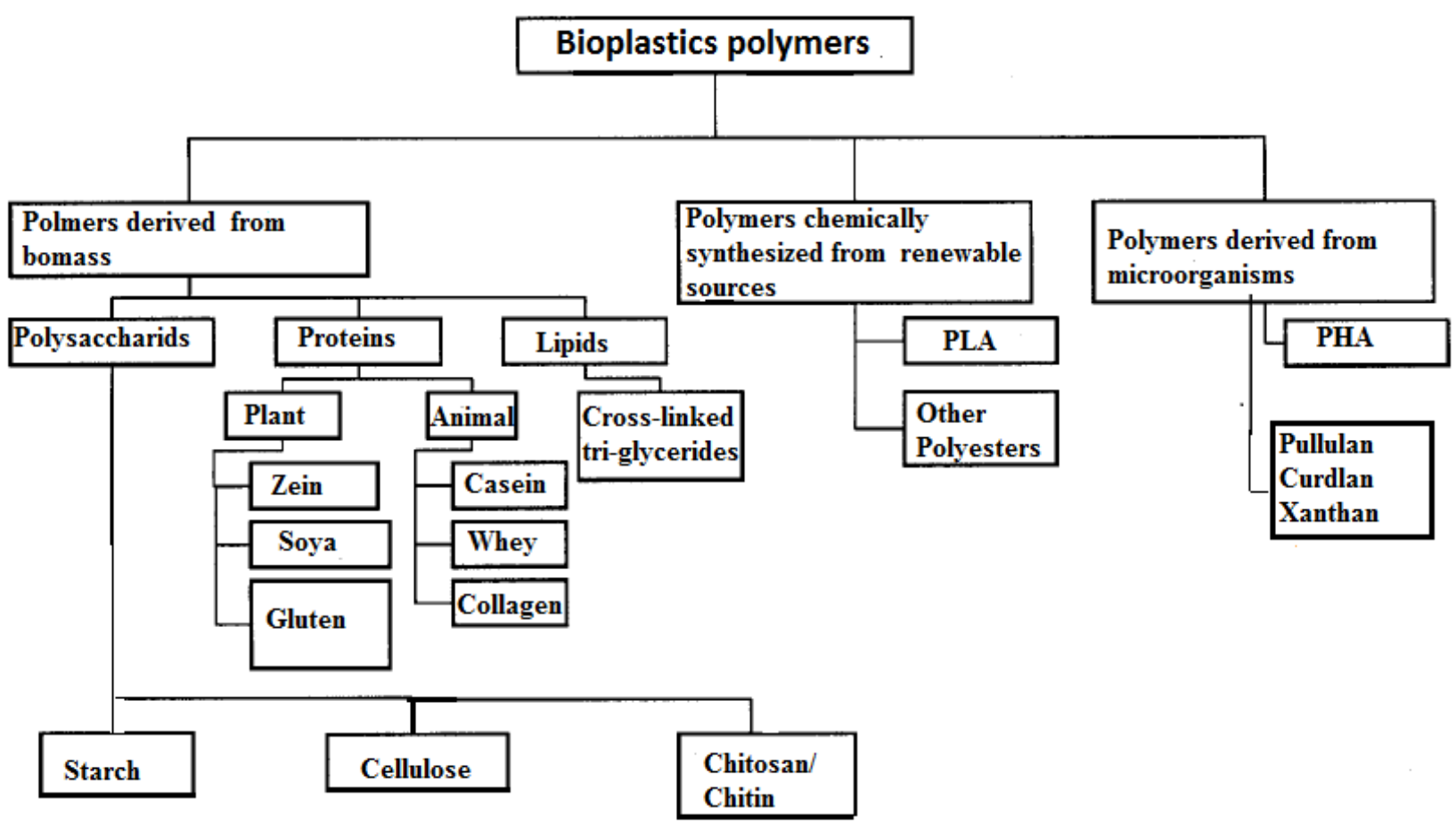

Biopolymer cellulose can be incorporated to the bio-based polymer mainly to improve the Young's modulus and tensile strength and to decrease the water vapor transmission rate. The PLA would be beneficial in reducing the film brittleness by incorporation of starch, glycerol, or other degradable polyester (Cabedo et al., 2006).

\section{Nanotechnology}

Nanotechnology is defined as the creation and development of structures with at least one dimension in the nanometer length scale $\left(10^{-9}\right.$ $\mathrm{m})$ and these structures are called nano composites which could exhibit modifications or create novel properties to the materials.

A good interaction between the nanofiller (discontinuous phase) and polymer matrix (continuous phase) is desired to modify the bioplolymer, which can be achieved through polymerization, melt intercalation, and solvent intercalation. Nanoparticles, mainly nanoclays (montmorillonite and kaolinite), are preferred to enhance the properties of biobased polymers (Peelman et al., 2013).

\section{Physical/chemical modification}

Another technique used for improving the performance of bioplastics is by chemical and/or physical modification. Such kinds of modification provide a beneficial effect on the barrier and mechanical properties in addition to enhancing the compatibility among polymers. Generally starch is modified to improve the hydrophobicity, making them compatible with other hydrophobic materials. Starch films reduces their water vapor 
transmission rate by the addition of citric acid because carboxyl $(-\mathrm{COOH})$ groups react with the hydroxyl $(-\mathrm{OH})$ groups present in starch and thus decrease the free $\mathrm{OH}$ groups. Also, there is inhibition of recrystallization and retrogradation due to the formation of strong hydrogen bonds. Further, the addition of citric acid, a cross-linking agent improves the mechanical properties of starch (Ghanbarzadeh et al., 2011). Gelatinized starch, when heated with lithium chloride $(\mathrm{LiCl})$ in the presence of some organic solvent, becomes water resistant and flexible also (Fang et al., 2005).

\section{Applications of bioplastics in food packaging}

Among the extensively used bio-based plastics, PLA is widely used. Moreover, the bioplastics nowadays have found applications for both short-shelf life products like fresh fruits and vegetables and long shelf life products, like potato chips and pasta. An overview of applications of bioplastics in food packaging is listed in table 1 .

In conclusion, nowadays biodegradable packaging materials are mostly used, which do not need high oxygen and water vapor barrier properties. The biopolymers also show some constraints about the performance, such as mechanical, barrier properties and cost, which can be improved by novel strategies, such as, blending, chemical or physical modifications, coatings or using nano techniques. Incorporation of nanoparticles is better way to improve the performance of biobased films. In the food industry, these are used as carry bags, plates and cutlery, film to pack short shelf-life food products, loose film in transport, etc. Thus, it can be concluded that bioplastics have great potential in food packaging applications and also do not harm the environment by breaking down into the organic matter.

\section{Future trend}

Comprehensive research is needed to improve the barrier properties and to maintain the food integrity. Further, research and development in the biodegradable polymers is the need of the hour because of human responsibility towards environment. That is the main driving force implementing the tremendous potential of biopolymers in future.

\section{References}

Auras, R., Singh, S. P., and Singh., J.J. (2005). Evaluation of oriented poly (lactide) polymers vs. existing PET and oriented PS for fresh food service containers. Packaging Technology and Science. 18:207-216.

Averous, L. and Pollet, E. (2012). Environmental Silicate NanoBiocomposites. Springer, London Heidelberg, New York Dordrecht,

Blakistone, B., and Sand, C.K. (2007). Using Sustainable Packaging Technologies to Respond to Consumer, Retailer, and Seafood Industry Needs. International Smoked Seafood Conference Proceedings, 75-79.

Cabedo, L., Feijoo, J. L., Villanueva, M.P., Lagaron, J.M., and Gimenez, E., (2006). Optimization of biodegradable nanocomposites based on a PLA/PCL blends for food packaging applications. Macromolecular Symposia 233, 191197.

Castilho, L.R., Mitchell, D.A. and Freire, D.M.G. (2009). Production of polyhydroxyalkanoates (PHAs) from waste materials and by-products by submerged and solid-state fermentation. Biores. Technol. 100, 5996_6009.

Clarinval, A. M., and Halleux, J. (2005). Classification of biodegradable polymers. In: Smith, R.(Ed.), Biodegradable Polymers for Industrial 
Applications. Cambridge: Woodhead Publishing Ltd, pp. 3-31.

Fang, J. M., Fowler, P. A., Escrig, C., and Gonzalez, R. (2005). Development of biodegradable laminate films derived from naturally occurring carbohydrate polymers. Carbohydrate Polymers 60, $39-42$.

Freitas, F., Alves, V.D., Reis, M.A., Crespo, J. G. and Coelhoso, I.M. (2014). Microbial polysaccharide-based membranes: Current and future applications. Journal of Applied Polymer Science 131, 40047-40058

Gemili,S., Yemenicioglu, A., and Altinkaya, S. A. (2009). Development of cellulose acetate based antimicrobial food packaging materials for controlled release of lysozyme. Journal of Food Engineering 90, 453-462.

Ghanbarzadeh, B., Almasi, H., and Entezami, A.A. (2011). Improving the barrier and mechanical properties of corn starchbased edible films: Effect of citric acid and carboxymethyl cellulose. Industrial Crops and Products 33, 229-235.

Haugaard, V.K., Danielsen, B., and Bertelsen, G. (2003). Impact of polylactate and poly(hydroxybutyrate) on food quality. European Food Research and Technology, 216(3), 233-240.

Haugaard, V.K., Udsen A.M., Mortensen, G., Hoegh L., Petersen, K., and Monahan, F. (2001). Potential Food Applications of Biobased Materials, An EUConcerted Action Project. Starch/Stärke, 53(5), 189-200.

Highlights in bioplastics, http://www.biodeg. net/fichiers/Highlights\%20in\%20Biopla stics\%20(Eng). pdf (last accessed: 10/10/2012)

Iotti, M., Fabbri, P., Messori, M., Pilati, F. and Fava, P. (2009). Organicinorganic hybrid coatings for the modification of barrier properties of poly(lactic acid) films for food packaging applications.
Journal of Polymers and the Environment 17, 10-19.

Jager, A. (2010). Ingeo $^{\text {TM }}$ polylactide een natuurlijke keus, presentation given at VMT conference: green packaging (9/12/2010).

Jain, R., and Tiwari, A. (2015). Biosynthesis of planet friendly bioplastics using renewable carbon source. J. Environ. Heal. Sci. Eng. 13, 11.

Jamshidian, M., Tehrany, E.A., Imran, M., Jacquot, M. and Desobry, S. (2010). Poly-lactic acid: Production, applications, nanocomposites, and release studies. Comprehensive Reviews in Food Science and Food Safety 9, 552-571.

Jayasekara R, Harding I, Bowater I and Lonergan G (2005). Biodegradability of a selected range of polymers and polymer blends and standard methods for assessment of biodegradation. Journal of Polymer and Environment, 13(3): 231-251.

Koide, S., and Shi, J. (2007). Microbial and quality evaluation of green peppers stored in biodegradable film packaging. Food Control, 18(9), 1121-1125.

Kokoszka, S., Debeaufort, F., Hambleton, A., Lenart, A. and Voilley, A. (2010). Protein and glycerol contents affect physico-chemical properties of soy protein isolate-based edible films. Innov. Food Sci. Emerg. 11, 503-510.

Majid, I., Thakur, M. and Nanda, V. (2018). Biodegradable packaging materials. Elsevier Inc.

Morillon V, Debeaufort F, Blond G, Capelle $M$ and Voilley A. (2002). Factors affecting the moisture permeability of lipid-based edible films: a review. Critical Reviews in Food Science and Nutrition, 42(1): 67-89.

Otles, S. and Otles, S. (2004). Manufacturing of Biobased Packaging Materials for the Food Industry. Acta Sci. Pol. 
Technologia Alimentaria, 3(2):13-17.

Peelman, N., Ragaert, P., Meulenaer, B. D., Adons, D., Peeters, R., Cardon, L., Van Impe, F., and Devlieghere, F. 2013. Application of bioplastics for food packaging. Trends in Food Science and Technology, 13: 116-131.

Quoc, L., Hoa, D., Ngoc, H.and Phi, T. (2015). Effect of xanthan gum solution on the preservation of acerola. Cercetari Agronomice în Moldova 48, 89-97.

Rasal, R.M., Janorkar, A.V., and Hirt, D.E. (2010). Poly(lactic acid) modifications. Progress inPolymer Science, 35, 338356.

Scott, G. and Wiles, D.M. (2001). Programmed-life plastics from polyolefins: A new look at sustainability. Biomacromolecules 2, 615-622.

Shukla, P. T. (1992). Trends in Zein Research and Utilization. Cereal Foods World, 37: 225 .

Siracusa, V., Rocculi, P., Romani, S., and Dalla Rosa, M. (2008). Biodegradable polymers for food packaging: A review. Trends in Food Science and Technology, 19(12), 634-643.

Song, J. H.,Murphy, R. J., Narayan, R. and Davies, G. B. H. (2009). Biodegradable and compostable alternatives to conventional plastics. Philosophical transactions of the Royal Society of London B-Biological Science 364, 2127-2139.

Sorrentino, A., Gorrasi, G. and Vittoria, V. (2007). Potential perspectives of bionanocomposites for food packaging applications. Trends in Food Science and Technology 18, 84-95.

Sudesh, K., and Iwata, T. (2008). Sustainability of Biobased and Biodegradable Plastics. CLEAN, soil, air, water, 36(5-6), 433-442.

Thakur, V.K. and Thakur, M.K. (2016). Handbook of sustainable polymers: Processing and applications; Pan Stanford Publishing: Singapore.

Tharanathan, R. N. (2003). Review biodegradable films and composite coatings: past, present and future. Trends in Food Science and Technology, 14, 71-78.

Tripathi, A.D., Srivastava, S.K. and Yadav, A. (2015). Biopolymers: potential biodegradable packaging material for food industry. In: Alavi, S., Thomas, S., Sandeep, K.P., Kalarikkal, N., Varghese, J., Yaragalla, S. (Eds.), Polymers for Packaging Applications. first ed. Apple Academic Press, Oakville, Canada, pp. 153-172.

Whistler, R.L.and BeMiller, J.N. (2007). Starches, modified food starches, and other products from starches. In: BeMiller, J.N. (Ed.), Carbohydrate Chemistry for Food Scientists. American Association of Cereal Chemists, St. Paul, MN, pp. 117_151. www.european-bioplastics.org. (2017). Yadav, A., Mangaraj, S., Singh, R., Mahanti, N., M and Arora, S. (2018). Biopolymers as packaging material in food and allied industry. International Journal of Chemical Studies, 6 (2): 2411-2418.

\section{How to cite this article:}

Rukhsana Rahman, Monika Sood, Neeraj Gupta, Julie D. Bandral, Fozia Hameed and Shafia Ashraf. 2019. Bioplastics for Food Packaging: A Review. Int.J.Curr.Microbiol.App.Sci. 8(03): 2311-2321. doi: https://doi.org/10.20546/ijcmas.2019.803.274 